$M F|J H L M O K N| J U H B P X A Y H A S G S v$

UDM H B D B H D R X D P L D L B E U B F V N K ।

A A T Y UANDOMG I UARUH I F GDNLIERNGM J b

A M O B A T T E R Y U C H A R G E I S T A T E I P R N G M D S U W

EKOR TRWPOI UZTRE - PMNE SWLNCAWZYKFE Q L O

MOF I HECEFHOKHES I D V U S G R V L R A K G E C L Z E M S,

TNB D I O S G B Z N J I OPNE O ONYAZTEFNAX JR C N I F Z KM.

DC I WREQR I UZTREWEYLINEWCLVVVHNVUA JKUVXESYM,

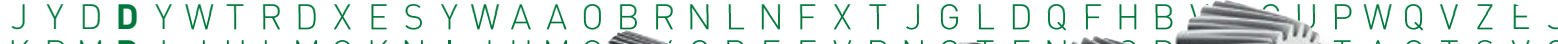

KPMR I JHLMOKN I JUMQ ZBTIDGLETUOADGJQPN

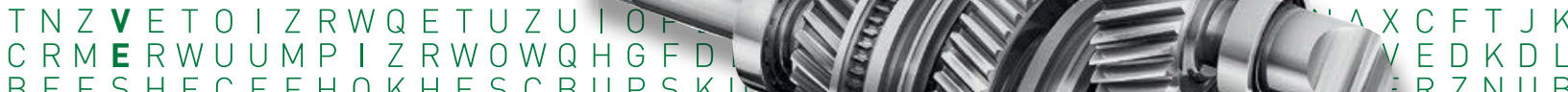
BEFSHECEFHOKHESCBUPSKUNDORZNUB

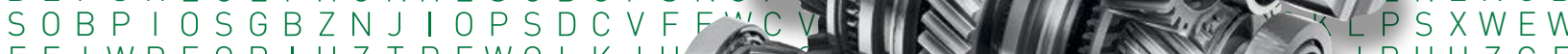

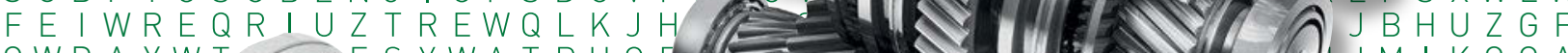
CWDAYWT $P J M F|J \&: N| J U H B Z$

C G T V D $J T Z G E$ VWM C R A K D P J

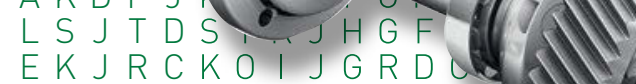
$M O T Y Q O G N T Z D S Q O K$ $T N U E|N R L U J G D| N$
$D C O O V C E S O P M N V C$ $J Y|Z Q Y A H| N C W Q Y$ N JKVNJRAKDOBNJ $A A O O U B N D O N G \mid \cup A R$

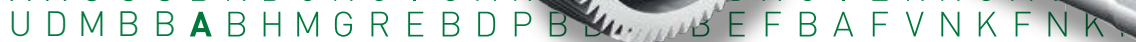
A A O E U T D ONG I UARNH IOGDNOIERNGMDSA Ell $M O T M J T U H B Z G S Q O M G D N \vee U S G R \vee L G R \vee K G E C L$ UDMELEDG J L Y C BMPBDLRBEFBAFVNKFNKRE FEI C U R R E N T Z TREWQLKJHGFDSAMMBVCXYM KNIJBHUZGF C I MNS YRECLPQACEZRWDXAYHBMWRZIRFVEGLZHNUJMIKOQA $P J M N|B H L M O K N| J U H B Z G V T F C R D X E S N W A S R E C V F H K N U T E Q T F$ C G T J D G ETUOADG JLYCBMWRZIPSFHKTVNZLMOIJEUHBZGWR J T Z UETOIZRWQETUOMBCYNVXADG J L K HESYSCBFGMHTILQNV 


\section{Electric Driving without Range Anxiety}

\section{Schaeffler's range-extender transmission}

\section{Andreas Kinigadner}

Dr. Eckhard Kirchner

D v

$J \mathrm{ZMH}_{2}$

$A G Q S W \mid\llcorner\ldots$

F I MBCHSEH七乞

I C E CBSTPO I O D C V ᄃ

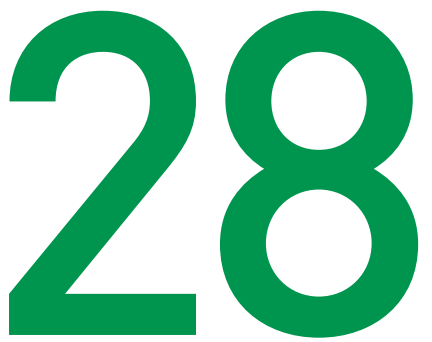

$D G \vee T Q U J X R E L K J H G F D S A N_{1} \ldots$

Y Y MRTX A G YWPHCE Q A YWS XE E C $R$,

$C X V N H O U B I J B Z G V T F C R D X E S N W A S K\llcorner$

Z VTFLUJADGYCBMWRZ I P S F H K T VNZLMU.

X DBPORUTETMBCYNVXADGJLKHESYSCBMB乙

DC SKUPOWRWZTWHNEDKUNWPONCALV I K Z TWH N

EHKLPFLKJKO I UZTREWQYXCVBNM I QWUO I UZTR L

WDXAYHASGSVNPIZRWQSCGZNJ|MNSTRVNPIZRWQ_

I LZUKOGIKCKPMNESWLNCXWZYKFEDIOPPMNESWLNCX

$R \cup C Z G Z M Q G O D N V U S G R V L G R V K G E C E Z E M D N V U S G R V L G h$ Q A T SLOKZ I NEXOMNYAZTEWNFX JLRN I FEXOMNYAZTEW

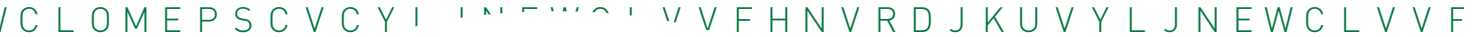
F A MUAN J Y O

KMNSR D O

L I EPN N

B S A T B

$P \mid E P^{\prime}$

$R \cup C Z$

B S A

D G V

$Y\llcorner\wedge$

CX

Z V

$X \mathrm{D}$
.11 O O G D D O I E K.

D D L R B E B A FVN

, UAH I OGDNOIERNGM

. OQODNVUSGR VLGR VKG

$P D B D D L R B E F B A F \vee N K F N$ r

, OTRELKJHGFDSAMMBVCX $X$ A Z YWPHCE Q A YWS XEE CR F I $O U B$ I JBZGVTFCRDXESNWAS U JRDGYCBMWRZIPSFHKTVN I R UTETMBCYNVXADG J L K HES I P OWRWZTWHNEDKUNWPONCA $F L K J K O \mid U Z T R E W Q Y X C \vee B N M$ HASESVNPIZRWQSCGZNJIM GIKCKPMNESWLNCXWZYKFF $+A S U S V N P \mid Z R W Q S C G Z N J$ । I KCKPMNESWLNCXWZYKF $10 X O D N V U S G R V L G R V K G$

1 I N EX OMNYAZTEWNF

' CYL JNEWCLVVFH' $\cap N \vee \cup S G R V L G F$ 


\section{Introduction}

Battery electric vehicles offer the option of emission-free local mobility. The range of these vehicles will remain limited in the foreseeable future due to high battery costs and the increased weight associated with the limited energy storage density. This has lead to the increasing development of range-extender drive systems during the last few years. These concepts in most cases use a serial hybrid drive, in which the internal combustion engine is operated solely as a generator. These are usually internal combustion engines specially developed for this application or sometimes stationary operated engines, for which a number of variants and even Wankel type engines have been proposed. However, the implementation of these special engines is associated with large investments and is frequently not feasible due to high cost pressures. In addition to the technical and commercial challenges of implementing this technology, serial hybrid drives have a poor tank-to-wheel efficiency on long distance routes.

The focus must therefore be placed on developing alternative solutions, particularly for electrification in the compact vehicle segments. Schaeffler's range-extender concept is based on adding a special transmission to an existing internal combustion engine to produce a full hybrid. A simple automatic spur gear transmission and an electric motor are used instead of a conventional automatic or double clutch transmission. The typical range of driving conditions for an electric vehicle can be completely covered at low system costs. A powertrain architecture with a direct mechanical linkage of the internal combustion engine improves the efficiency balance of a vehicle over long distances. In addition, Schaeffler's range-extender transmission allows automobile manufacturers to imple- ment a modular drive strategy without carrying out fundamental changes to the vehicle architecture.

\section{Concept}

\section{What is a range extender?}

A range-extender vehicle differs from a hybrid vehicle in that it can be operated with the electric motor only during day-to-day operation. This also includes acceleration and high-speed driving. There is no clear distinction between range extenders and plug-in hybrid vehicles, whose batteries can be charged from a power socket. The range extender is sometimes even described in technical literature as a type of plug-in hybrid [1].

Most range extender vehicles were originally designed as serial hybrids, i.e. the internal combustion engine is operated only as the drive for an electric generator. The most prominent example from the pioneer age of the automobile is the Mixte car developed by Ludwig Lohner and Ferdinand Porsche in 1902. The overall efficiency of this type of system architecture is not only dependent on the efficiency of the engine and generator, but also on the losses during charging and discharging of the battery.

At high driving speeds, a serial hybrid drive has a lower overall efficiency than a direct drive by means of an internal combustion engine due to conversion losses [2]. This is why some range-extender vehicles are already equipped with a power-splitting hybrid drive system. A selectable mechanical fixed drive ensures optimum overall efficiency in this case.

A comparison between the powertrain concept of the Opel Ampera, which has a 


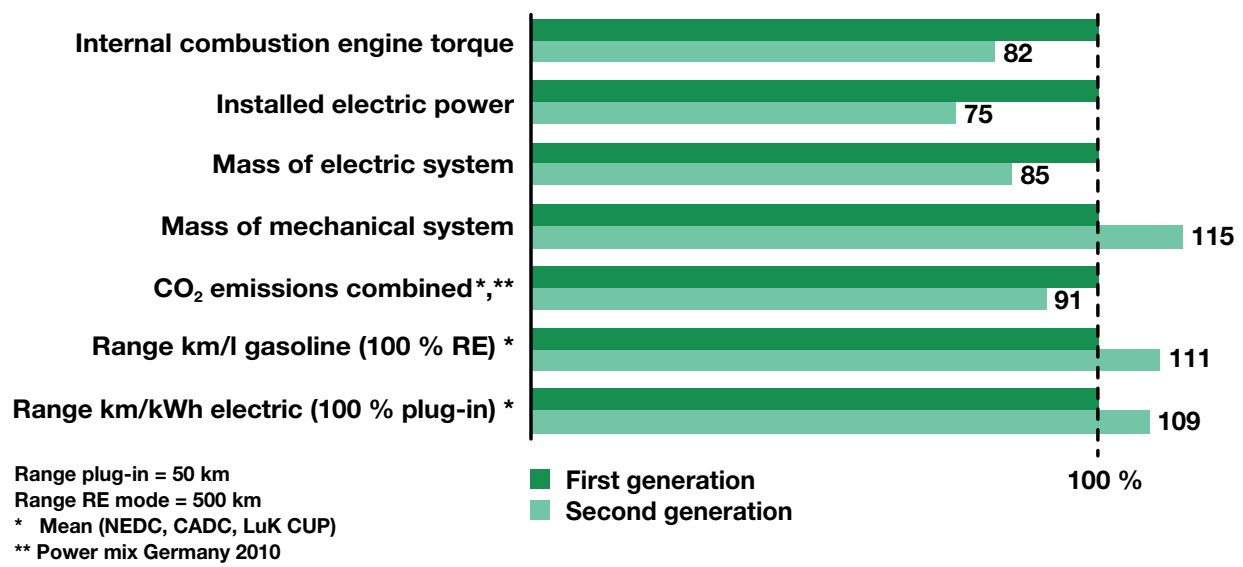

Figure 1 Comparison of performance criteria for a serial hybrid and a vehicle of identical performance with a powertrain similar to the Ampera.

mechanical fixed drive, and a conventional serial hybrid shows the significant advantages with regard to $\mathrm{CO}_{2}$ emissions $(-9 \%$ in combined mode, Figure 1). At the same time, the range of electric operation also increases by $9 \%$ [3]. This type of configuration does however have disadvantages: An additional clutch and a more complex operating strategy are required. In addition, the spatial arrangement of the generator unit comprising the internal combustion engine and generator can no longer be freely selected in the vehicle.

\section{A range extender for the $B$ and $C$ segment}

Range-extender vehicles with on-demand mechanical drive are particularly suitable for vehicles that are mainly driven in short-run operation, but are occasionally also used for longer interurban journeys. This makes the range extender particularly attractive for the $\mathrm{B}$ and $\mathrm{C}$ segment, the more so since this segment accounts for high quantities worldwide. If such a drive can be produced in line with market requirements, it would fill a gap between
- expensive range-extender vehicles, which can cover large distances with an internal combustion engine after draining the battery (for example, the Opel Ampera)

- and battery electric vehicles in the A segment, which have no range problems in urban traffic despite having a low battery capacity (for example, the VW up!).

The $\mathrm{B}$ and $\mathrm{C}$ segments are under a high degree of pressure from competitors internationally so it is necessary to produce a range-extender solution at very low costs. Schaeffler therefore aimed to simplify the conventional range-extender concept during development as follows:

- Re-utilization of the internal combustion engine and its characteristics in terms of function and interfaces

- No change in the design envelope, no change of vehicle architecture in conventional front transverse powertrain platforms

- Use of only one electric motor

- Use of a single electromechanical actuator if possible

- Simplification of the transmission by using three or even only two gear steps. 


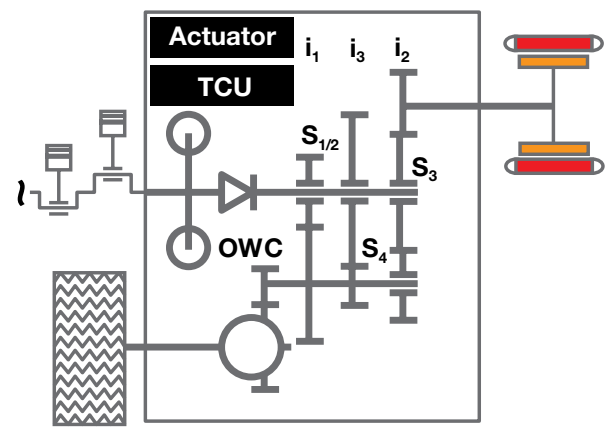

Figure 2 Schematic diagram of Schaeffler's range-extender module with three mechanical gears

\section{Basic concept}

Preliminary considerations led to the schematic diagram of the powertrain shown in Figure 2.

The range-extender module is connected to the internal combustion engine using an one-way clutch (OWC), which can, for example, be designed as a roller clutch. The electric motor is also connected in a selectable manner by means of a separate input shaft. The input shaft can drive the front axle differential (FD) and thus the wheel directly via the gear step freewheel (S4). Three additional, fully independent selectable speed gears (S1, S2 and S3) can be used to connect the internal combustion engine to the output shaft and to manage gearshift operations. The signifi- cant simplification of the transmission and the associated reduction in costs compared to current hybrid vehicle designs are immediately apparent.

\section{Design}

Schaeffler's range-extender transmission is a current advanced development project. The following information does not therefore refer to a specific transmission design but describes the ideas on which the design of the prototype is based. Figure 3 shows the prototype design, which has not yet been optimized for specific vehicle and powertrain dimensions.

It can be seen that the majority of components used in the range-extender transmission are components currently used in volume production. This means it was possible to use synchro ring packages operated by shift sleeves from manual transmissions [4]. The actuator driven by an electric motor with an interlock function, which Schaeffler

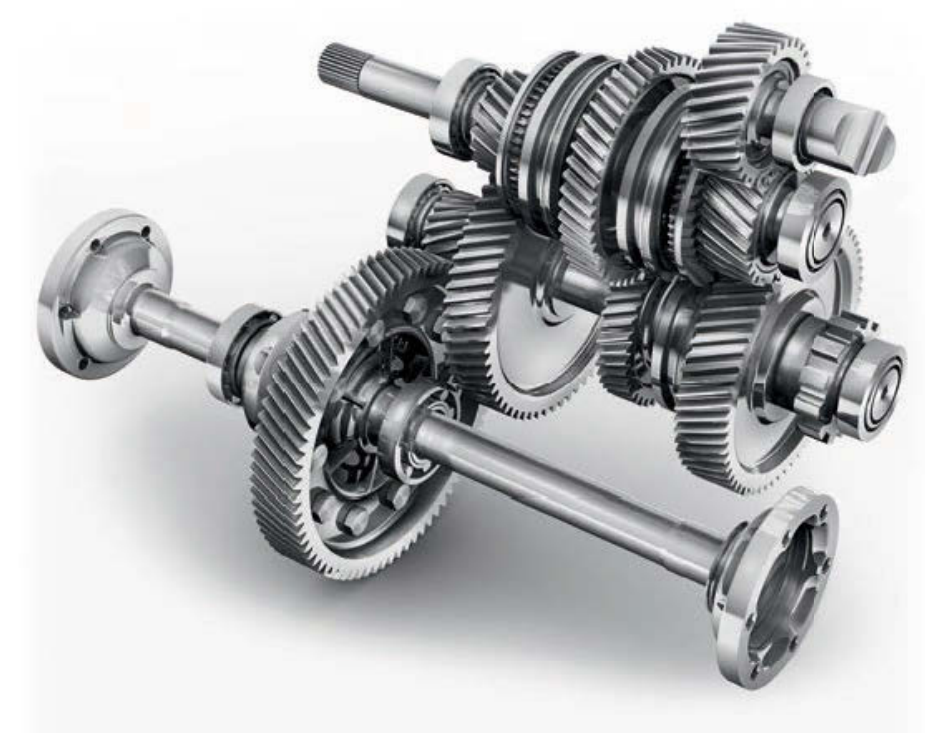

Figure 3 Power transmission design in the range-extender transmission 
developed for double clutch transmissions, can, in principle, be used for clutch actuation [5]. In contrast to conventional transmissions such as a manual or double clutch transmission, a separate reversing gear is not required for reverse gear in the range-extender transmission. The design offers a high level of freedom for the shaft arrangement due to elimination of multiple tooth meshes. This has major advantages with regard to the packaging space and integration.

\section{Function}

\section{Power transmission}

Under the above mentioned premises of a vehicle that is mainly driven in electric mode, the hybrid transmission shown in Figure 3 enables the use of three gears with a total of only five gear meshes for both the electric motor and the internal combustion engine. The internal combustion engine can only be used above a speed of $10 \mathrm{~km} / \mathrm{h}$ due to the omission of a launch device, which does not cause any restrictions because the electric motor covers these operating conditions.

The design of the gear set enables the tractive force to be increased by the internal combustion engine in electric mode and vice versa, i.e. both drives assist each other reciprocally. In this regard, it is important to select the shift point so that the engagement of the internal combustion engine is not perceived as an impairment of comfort. Figure 4 shows a schematic sawtooth diagram for vehicle operation with a well charged battery. The shift point for engaging the electric motor can be freely selected from a large range.

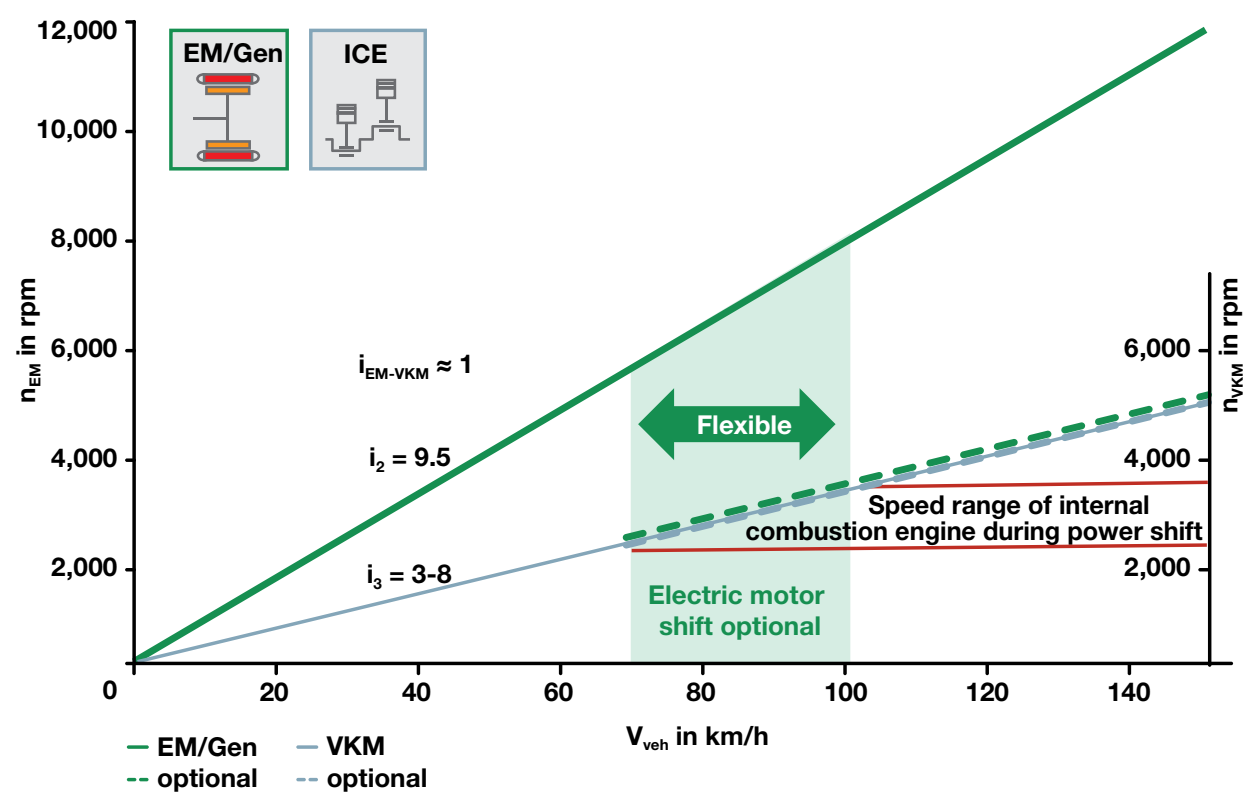

Figure $4 \quad$ Vehicle operation with the battery in a high state of charge 


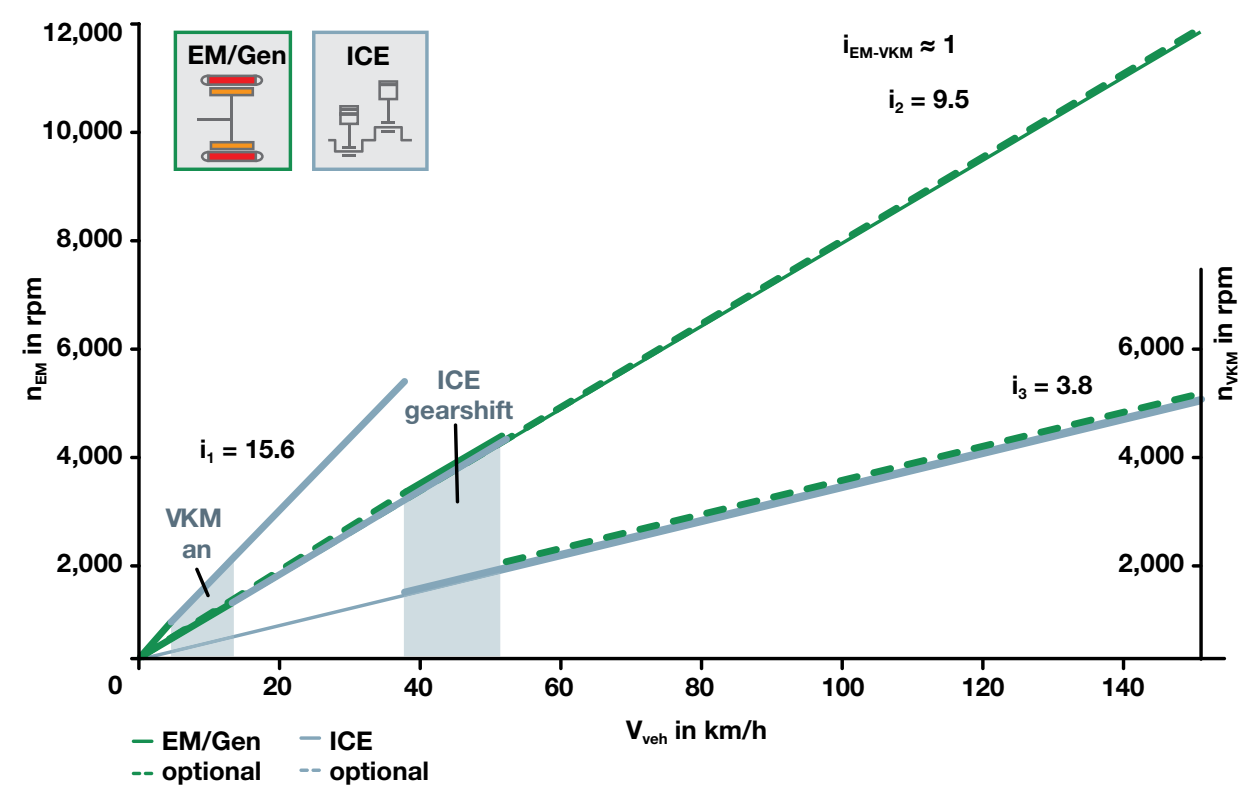

Figure $5 \quad$ Vehicle operation with the battery in a low state of charge

Figure 5 shows the sawtooth diagram with the battery almost fully discharged. If the battery has an insufficient state of charge, it must be charged for a short time while the vehicle is stationary before starting. The battery can be recharged during vehicle operation at high speeds in the power-splitting mode and also if the driver wishes to accelerate slowly to moderately while driving. The possibility of a breakdown due to a flat battery can therefore be eliminated by using an intelligent charging strategy in conjunction with the maximum possible load point shift if the internal combustion engine during vehicle operation.

\section{Operating conditions}

Six different power flows, which each correspond to an operating condition, can be selected with the three ratio stages and three shifting elements that are independent of each other.

\section{Condition 1:}

\section{Generator mode}

The parking lock can be activated in generator mode. The internal combustion engine drives the generator via the gear wheel S3, Figure 6.

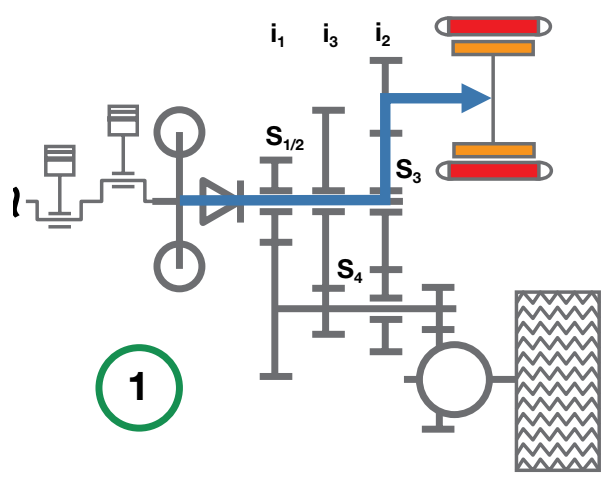

Figure 6 Power flow in generator mode 


\section{Condition 2:}

Vehicle launch and reverse driving

Vehicle launch is only possible in electric mode due to the selected ratios and the working ranges of the internal combustion engine and electric motor. The internal combustion engine is switched off, shift element $\mathrm{S} 3$ is open and S4 is closed. The drive function both in a forwards and reverse direction is now taken over by the electric motor only, Figure 7.

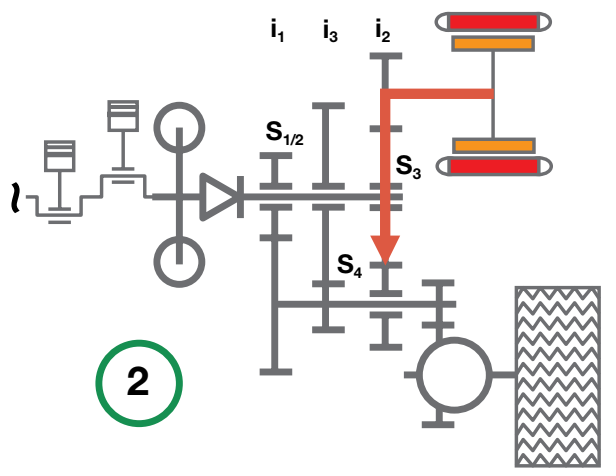

Figure 7 Power flow in electric mode

All driving conditions can be overcome during urban operation in all-electric mode provided that the battery has a sufficient state of charge. Shifting is not necessary until approximately $50 \mathrm{~km} / \mathrm{h}$. Reversing with the internal combustion engine powertrain is not possible with the selected design, but is also not necessary.

\section{Condition 3:}

\section{Hybrid city driving}

If the battery is in a low state of charge or when driving uphill, the internal combustion engine can even be used in first gear at speeds between 5 and $10 \mathrm{~km} / \mathrm{h}$ depending on the specific design. The ratio enables crawling at slow speeds. The electric motor can be used as a generator or a

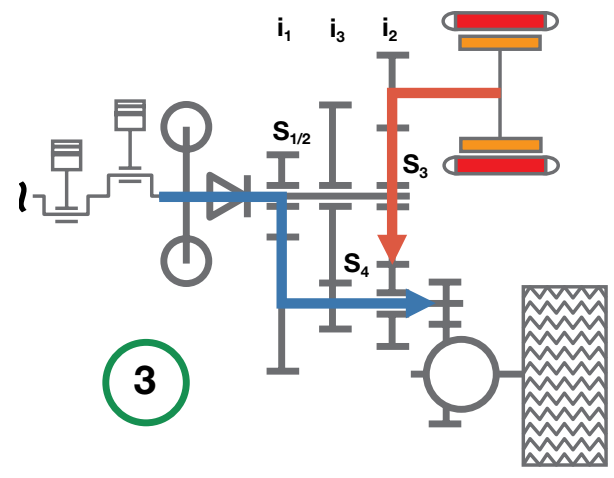

Figure 8 Power flow during hybrid city driving

drive depending on the battery's state of charge. First gear is mainly used by the internal combustion engine, $\mathrm{S} 1$ is closed and the electric motor can be connected via S3 or S4.

\section{Condition 4: \\ Hybrid drive at moderate speeds}

If the battery is in a low state of charge, the internal combustion engine can be operated in second gear at driving speeds above the speed range of first gear. Shift element S3 is closed again and $\mathrm{S} 1$ or $\mathrm{S} 2$ is opened for this purpose, Figure 9.

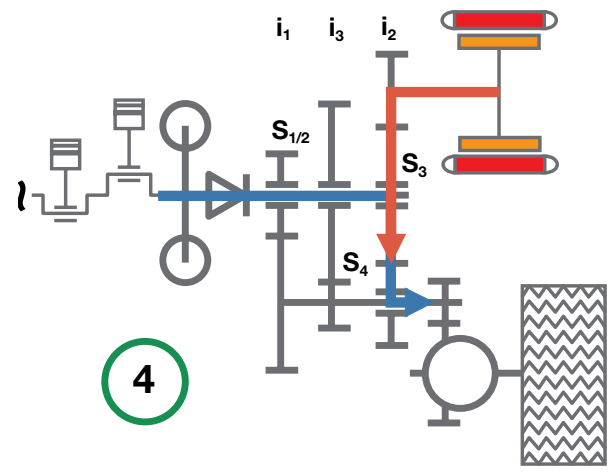

Figure 9 Power flow at moderate speeds in hybrid mode 
By designing the operating strategy appropriately, it is also possible in condition 4 to use some of the torque produced by the internal combustion engine for operating the electric motor as a generator via gear wheel S3 if the battery is in a low state of charge.

\section{Condition 5:}

\section{Accelerating to high speeds}

If a vehicle equipped with Schaeffler's range extender leaves the urban zone, the internal combustion engine can be engaged in order to rapidly reach high speeds. The internal combustion engine is then engaged via the third gear by closing the shifting element S2, Figure 10. Presynchronization is carried out by matching the speed of the internal combustion engine.

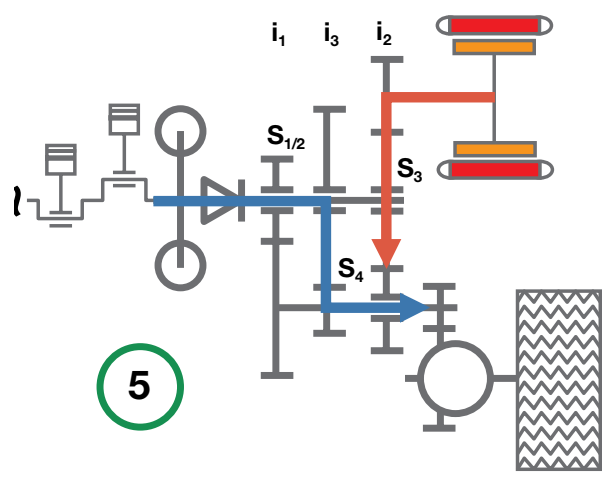

Figure 10 Power flow during high acceleration

The electric motor also provides accelerating power via second gear so that high torque and good acceleration values can be achieved.

\section{Condition 6:}

\section{Driving at high speed}

After the vehicle reaches the required speed, it is also advisable to direct the power flow of the electric motor via third gear. Shifting element S3 is opened and S4 is closed at the same time for this purpose, Figure 11.

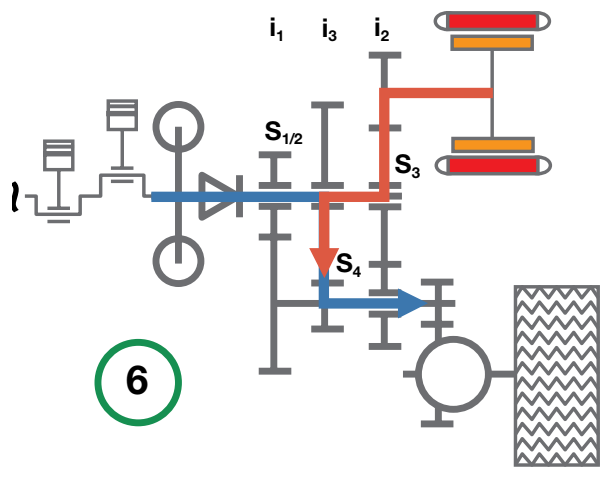

Figure 11 Power flow at high speed

Power split operation, in which the internal combustion engine is used to charge the battery via the generator, is also possible in this shifting condition when no electric acceleration power is requested.

Figure 12 shows a summary of the possible power flows and the required actuator positions. It is clear that due to the sequential gearshift system, the torque flow during gearshifts is not interrupted because one of the two torque paths in the transmission is always closed. Furthermore, generator mode is possible at any time due to the connection between the electric motor and the wheel.

\section{Operating strategy}

The operating strategy for the range-extender transmission is mainly dependent on three parameters:

- The battery's state of charge (SOC)

- The torque required by the driver (position of the accelerator pedal)

- Current speed range (urban/rural roads/highway).

One possible operating strategy enables all-electric mode within a speed range of 70 to a maximum of $120 \mathrm{~km} / \mathrm{h}$ if the battery is sufficiently charged. The internal 


\begin{tabular}{|l|c|c|c|c|c|}
\hline Operating condition & & $S_{1}$ & $S_{2}$ & $S_{3}$ & $S_{4}$ \\
\hline Neutral/generator & 1 & 0 & 0 & 1 & 0 \\
\hline EM i $/$ reverse & 2 & 0 & 0 & 0 & 1 \\
\hline Hill mode & 3 & 1 & 0 & 0 & 1 \\
\hline EM/EM + ICE $\mathrm{i}_{1}$ & 4 & 0 & 0 & 1 & 1 \\
\hline Power shift & 5 & 0 & 1 & 0 & 1 \\
\hline EM/EM + ICE $\mathrm{i}_{2}$ & 6 & 0 & 1 & 1 & 0 \\
\hline
\end{tabular}

Figure 12 Shift pattern of the range-extender transmission $(0=$ open, $1=$ closed $)$

combustion engine can intervene and provide assistance during high acceleration if this is not prevented by an operating strategy which is aimed at ensuring emission-free local mobility. The internal combustion engine is engaged above a defined speed, for example, $50 \mathrm{~km} / \mathrm{h}$. At higher speeds, particularly during operation on highways or for long distances, the internal combustion engine is always switched on in order to achieve optimum overall efficiency.

The internal combustion engine is also engaged in urban areas if the battery has a low state of charge. This is in accordance with current design criteria for serial hybrid drives. The share of power generated electrically is greatly reduced and is completely switched off at high speeds. If the driver wishes to accelerate strongly, the electric power output is limited depending on the condition of the battery. The internal combustion engine provides the missing torque in order to fulfill the torque requirements of the driver. Firstly, this means the required driving performance can be achieved and secondly the electric motor can also serve as a generator. This always ensures the battery is in a state of charge, which enables vehicle launch using only electric power. It is possible to warn the driver via a signal that charging of the battery is urgently required. With the selected design, this can be carried out at charging stations but also when the vehicle is stationary with the engine running (operating condition 1 , see above). Alternatively, it is also possible to charge the battery using the engine's generator if this was not omitted for cost reasons. Charging power of up to $3.6 \mathrm{~kW}$ can be achieved with this type of solution, which is equal to a normal AC power supply connection.

The internal combustion engine can still be started using the low-voltage battery if the high-voltage battery is fully depleted. However, launching is not possible immediately because the vehicle must initially produce sufficient power while stationary to continue the journey.

\section{Simplification to two gears?}

The initial approach of using a simple transmission with three gears can be further simplified by omitting the first gear, Figure 13. The internal combustion engine and electric motor can be oper- 


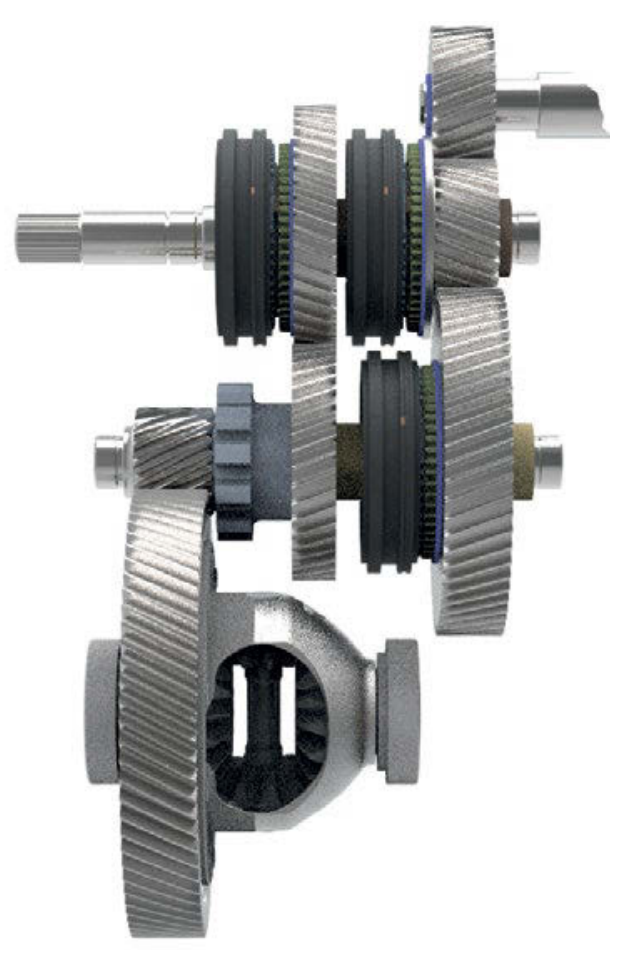

Figure 13 Simplification to a two-speed design

ated in both gears and gearshifts without an interruption of the tractive force are still possible. The design envelope, the mass as well as the complexity of the gearshift system can be minimized due to the reduced structure. The background for this simplification is the optimized cost-benefit ratio of the system because a vehicle equipped with a twospeed solution or the three-speed design must always launch using electric power only, although the internal combustion engine can only be engaged above 10 to $20 \mathrm{~km} / \mathrm{h}$. If the battery is in a high state of charge, a vehicle equipped with this variant would be driven in one gear using electric power only as far as possible and the internal combustion engine would not be engaged until high speeds are reached. All the operating conditions of hybrid driving can also be realized.

A vehicle breakdown due to the system-related necessity of a purely electric launch and the use of only one electric motor is unlikely due to the operating strategy. In addition, the recuperation characteristics can be designed so that the ease of electric launch is always ensured. The minimalist approach with only two gears therefore offers a more cost-effective but still functional alternative to the three-speed variant presented.

\section{Simulation}

The range-extender transmission developed by Schaeffler has already undergone initial testing in different simulations. It was important to determine the potential for reducing $\mathrm{CO}_{2}$ and to test the behavior under extreme driving conditions. The focus is placed on the twospeed variant in order to show the possibilities offered by Schaeffler's concept with regard to the reduction in fuel consumption that can be achieved.

The vehicle model designed in Matlab Simulink corresponds with typical values in the $\mathrm{C}$ segment. The assumed values were a vehicle weight of $1,450 \mathrm{~kg}$ and a four-cylinder naturally aspirated engine with a nominal power of $62 \mathrm{~kW}$ at $5,000 \mathrm{rpm}$ and maximum torque of $130 \mathrm{Nm}$ at 3,500 rpm. The electric motor has a nominal power of $60 \mathrm{~kW}$ and a torque of $200 \mathrm{Nm}$ (continuous) or $300 \mathrm{Nm}$ (peak).

The battery size of $9 \mathrm{kWh}$ was selected so that a guaranteed range of electric operation of $30 \mathrm{~km}$ can be achieved. This is a conservative assumption based on an op- 


\begin{tabular}{|l|c|c|c|c|}
\hline Gearshift and NEDC & \multicolumn{2}{|c|}{ Base ratio EM } & \multicolumn{2}{c|}{ Long ratio EM } \\
\hline Vehicle speed at EM shift in km/h & 45 & 90 & 45 & 120 \\
\hline Fuel consumption in $\mathrm{g} \mathrm{CO}_{2} / \mathrm{km}$ & 58 & 60 & 58 & 61 \\
\hline
\end{tabular}

Figure 14 Initial simulation results

erating strategy in which a battery with a SOC of $40 \%$ is regarded as "almost fully discharged".

In addition, two ratios for the second gear were modeled. With the base ratio of 3.8, the gearshift takes place at a speed of $90 \mathrm{~km} / \mathrm{h}$ in operating condition 6 , while with the longer ratio of the electric motor the gearshift is not made until $120 \mathrm{~km} / \mathrm{h}$. Alternatively, a significantly lower shifting point of $45 \mathrm{~km} / \mathrm{h}$ was used for the simulation. Figure 14 shows the simulation results for the NEDC test cycle.

The results achieved in the initial simulation are encouraging. Firstly, the assumptions, for example, with regard to the inertia class and the useable battery capacity are very conservative and these could be significantly more favorable in a lighter vehicle with optimized battery management. Secondly, the consumption levels of the internal combustion engine could be reduced if a smaller engine with a higher power density is used as is increasingly the state-of-theart. Thirdly, the SOC of the battery was higher after running the cycle than at the start, which is not a requirement in the certification regulations. 10 to $12 \mathrm{~g} \mathrm{CO}_{2} / \mathrm{km}$ alone could be saved by making a corresponding adjustment to the operating strategy.

From the current perspective, it is likely that Schaeffler's range-extender concept can achieve a certified emission level of $50 \mathrm{~g} \mathrm{CO}_{2} / \mathrm{km}$ for the assumed C segment vehicle. A comparison shows what influence the useable battery capacity and vehicle mass has on fuel consumption. A shorter distance can be driven using electric power only with a useable battery capacity of $60 \%$ than if the useable battery capacity is increased to $75 \%$. For the cycle consumption, this increase in the battery capacity means approximate $14 \%$ reduction in the fuel consumption or $\mathrm{CO}_{2}$ emissions with the above assumptions.

In addition to the benefits with regard to fuel consumption, the acceleration values of 0 to $100 \mathrm{~km} / \mathrm{h}$ in less than $11 \mathrm{sec}$ onds show that driving pleasure is not sacrificed either in combined or all-electric mode. It was also important to verify the functional capability of the rangeextender transmission during extreme driving maneuvers, particularly on steep gradients. The results are also encouraging here:

- The electronically limited maximum speed of approximately $150-160 \mathrm{~km} / \mathrm{h}$ is safely reached on a typical highway gradient of $6 \%$.

- All gradients of practical relevance can be overcome at the low speeds in actual road traffic.

Even challenging requirements such as accelerating uphill can be carried out with the available battery charge either in combined or all-electric mode. 


\section{Summary and outlook}

The Schaeffler range-extender concept shows potential for realizing a rangeextended electric vehicle with significantly reduced system power and costs. The use of only one electric motor and a very simple transmission allows this concept to be integrated into a conventionally driven vehicle cost-effectively.

\section{Literature}

[1] Hofmann, P.: Hybridfahrzeuge: Ein alternatives Antriebskonzept für die Zukunft. Wien: Springer, 2010

[2] Kirchner, E.: Leistungsübertragung in Fahrzeuggetrieben. Berlin: Springer, 2007, p. $559 \mathrm{ff}$.

[3] Najork, R. et al.: What's the Transmission Content in E-Mobility? $10^{\text {th }}$ International CTI Symposium, 2011

[4] Hirt, G.; Massini, S.: Gearshift systems and synchronization: At the threshold of mechatronics. $9^{\text {th }}$ Schaeffler Symposium, 2010

[5] Bruno M.: Transmission actuators. $10^{\text {th }}$ Schaeffler Symposium 2014

Open Access. This chapter is distributed under the terms of the Creative Commons Attribution Noncommercial License, which permits any noncommercial use, distribution, and reproduction in any medium, provided the original author(s) and source are credited. 